http://jmscr.igmpublication.org/home/ ISSN (e)-2347-176x ISSN (p) 2455-0450 crossref DOI: https://dx.doi.org/10.18535/jmscr/v7i8.52

\author{
Journal Of Medical Science And Clinical Research \\ IGM Publication \\ An Official Publication of IGM Publication
}

\title{
Cardiac manifestation of HIV infection
}

Authors

\section{Dr Kavita Bendwal ${ }^{1}$, Dr Suresh Bendwal ${ }^{2}$, Dr S. B.Gawarikar ${ }^{3 *}$, Dr R. G. Dhawale \\ ${ }^{1,2}$ Assistant Professor, ${ }^{3}$ Professor \& HOD, ${ }^{4}$ Professor ${ }^{1,2,3 \& 4}$ Dept. of General Medicine, RD Gardi Medical College, Ujjain (M.P.), India \\ *Corresponding Author}

Dr Suresh Bendwal

Assistant Professor, Dept. of General Medicine, RD Gardi Medical College, Ujjain (M.P.), India

\begin{abstract}
Background: With the advent of effective anti-retroviral therapy (ART), HIV is becoming chronic disease. Patients with human immunodeficiency virus (HIV) on ART can expect to live longer, as a result various cardiac complications are increasing in patients of HIV. The aim of present study was to find out the prevalence of various cardiac manifestation in patients of HIV infection.

Material and Method: 100 patients of HIV were included in this study. All patients didn't have any previous cardiac illness and all were non alcoholic. ECG and echocardiographic evaluation done in all patients to find out various cardiac manifestation.

Results: Total 100 patients were studied. Abnormal ECGs seen in 52 patients commonest being sinus tachycardia followed by nonspecific ST-T changes. Abnormal 2D echocardiographic findings observed in 57 patients commonest being diastolic dysfunction followed by valvular leak and myocardial involvement. These abnormalities may be multifactorial including low CD4 counts, antiretroviral therapy, stage of HIV infection, opportunistic infection, cardiac autoimmunity and micronutrient deficiency.

Conclusion: The present study showed cardiac abnormalities in HIV patients in form of abnormal ECGs and abnormal 2D echocardiography. And these cardiac abnormalities are more prevalent in advanced HIV disease and AIDS.

Keywords: Human Immunodeficiency Virus, Acquired Immunodeficiency Syndrome, Anti-retroviral Therapy.
\end{abstract}

\section{Introduction}

HIV is an abbreviation used for Human Immunodeficiency Virus. It is a pandemic disease which had already affected 36.7 million people worldwide until 2015. ${ }^{1}$ As per the HIV estimation, at the end of year 2017, it was estimated that 2.1 million people living with HIV with 88000 new HIV infections and 69000 AIDS-related deaths in India. ${ }^{2}$ It is a multisystemic disease, which involve cardiovascular, respiratory, hematologic and central nervous system.
As a result of longer survival in HIV patients due to anti-retro viral drugs, stupendous efforts by various national, international organizations like WHO, various NGOs the patients with HIV infection are now living longer than ever before. As these patients live longer, more manifestations of late stage HIV infection will be seen, including HIV related cardiac disease. ${ }^{3}$ Cardiac involvement has been reported with increasing frequency in the recent years. The prevalence of cardiac 
involvement in AIDS patients has been reported to range between 28 to $73 \%{ }^{4}$

The cardiac involvement in HIV infected patients can occur due to a variety of causes like HIV infection itself, opportunistic infections caused by viruses, fungi and protozoa, side effect of antiretroviral drug and a combination of these factors. Direct infection of target tissue with HIV, inflammation and immunosuppression secondary to HIV infection, and common comorbidities such as alcohol and drug abuse may all contribute to impairment of cardiac function. ${ }^{5}$

The advent of potent highly active antiretroviral therapy (HAART) for persons infected with HIV1 has led to a "new" chronic disease with complications including cardiovascular disease (CVD), HIV associated cardiomyopathy (HIVAC). Both are a significant cause of morbidity and mortality in persons with HIV infection. In addition to traditional risk factors such as smoking, hypertension, insulin resistance and dyslipidemia, infection with HIV is an independent risk factor for CVD. ${ }^{3,7}$

Acquired immunodeficiency syndrome (AIDS) is characterized by an acquired, profound, irreversible immune suppression that predisposes patients to multiple opportunistic infection, malignant neoplasms and a progressive dysfunction of multiple organ systems.

In view of the increasing incidence of HIV infection and longer survival, the present study was conducted to focus on cardiac manifestations in patients with HIV infection.

Study Design: Observational Study

\section{Material \& Methods}

The present study was conducted on 100 patients of HIV in the period of Feb 2018 to Jan 2019.

Inclusion Criteria- Patients of HIV with age group between 16 to 60 years attending ART center, medicine OPD and IPD in our institute with no previous history of any cardiac illness and non-alcoholic were included in this study. All patients were diagnosed as HIV as per recommendation of WHO.
Exclusion Criteria- Patients of congenital heart disease, ischaemic heart disease prior to HIV diagnosis, rheumatic heart disease, renal disease, patients less than 16 and more than 60 years of age, alcohol consumers were excluded. Any medications that are known to alter cardiac functions were not given to the patients.

All patients were on conservative treatment. A pre-informed consent was obtained. All patients were subjected to detailed history, anthropometric measurement (BMI), clinical examination and biochemical investigations including lipid profile, blood sugar, blood urea, serum creatinine, serum electrolytes, CD4 count and urine examination. ECG and echocardiography examinations of all patients were performed. All patients of HIV were divided into 4 groups according to WHO staging according to their CD4 counts. Results obtained in all patients with HIV, prevalence of cardiac involvement seen in all 4 groups. Statistical analysis was done. $\mathrm{P}$ value $<0.05$ was taken as significant.

\section{Observation}

100 patients of HIV were studied. All patients were non alcoholic and have no history of any cardiac illness prior to HIV diagnosis. Out of 100 patients, 68 were males and 32 were females. Physical characteristics of all studied HIV patients were shown in Table I. 62 patients were receiving ART for a mean duration of 16.08 months.

All patients were divided into 4 groups according to their WHO staging (applicable for adults and children aged $>5$ years) as shown in table II. According to WHO (World health organization) there are 4 staging of HIV infection based on their CD4 counts. Stage I includes patients of HIV with CD4 counts > 500 cells $/ \mathrm{cmm}$, stage II includes patients of HIV with CD4 counts between 350 to 499. Stage III is advance HIV disease (AHD) in which CD4 count is between 200 to 349 . Stage IV is acquired immune deficiency syndrome (AIDS) in which CD4 count is less than 200 cells $/ \mathrm{cmm}$.

Stage I having 13 patients, stage II having 20 patients, stage III having 22 patients and in stage 
IV there are 45 patients. In all, 55 patients had HIV disease and remaining 45 patients had AIDS (WHO stage 4).

In all patients chest X-ray, ECG and 2D echocardiography was performed. On the chest Xray PA view, cardiomegaly was observed in 15 patients. Of these 2 patients had dilated cardiomyopathy with severe LV systolic dysfunction. ECG finding seen in all 4 stages as shown in table III. Abnormal ECG findings was reported in 52 patients, sinus tachycardia being the commonest $(\mathrm{n}=25)$ followed by nonspecific ST-T changes ( $\mathrm{n}=17)$, left ventricular hypertrophy $(\mathrm{n}=14)$, low voltage complexes $(\mathrm{n}=13)$ and intraventricular conduction defects $(n=8)$.

2D echocardiography finding seen in all 4 stages as shown in table III. 2D echocardiography findings were abnormal in $57 \%$ patients (57 out of 100). Diastolic dysfunction being the commonest (grade I to grade IV) seen in 27 patients, followed by valvular leak seen in 24 patients, of these MR being the commonest then TR and AR. Left ventricular hypertrophy seen in 22 patients. Pericardial involvement (pericarditis \pm pericardial effusion) seen in 11 patients, moderate pericardial effusion in 2 patients, mild in 5 Patients. Cardiac tamponade not seen in any patients. Myocardial involvement (myocarditis and cardiomyopathy) in form of LV systolic dysfunction seen in 9 patients (Severe LV dysfunction (LVEF < 35\%) in 5 patients). Of these 5 patients were having regional wall motion abnormalities and 4 patients were having global hypokinesia including 2 patients of dilated cardiomyopathy. Infective endocarditis seen in 1 patients. Pulmonary hypertension (PASP $>30 \mathrm{~mm} \mathrm{Hg}$ ) observed in 14 patients, none of them had any past history of chronic respiratory illness.

Table No. I Physical and biochemical characteristics of HIV patients

\begin{tabular}{|c|c|c|}
\hline S. No. & Characteristics & Cases $(n=100)$ \\
\hline 1. & $\begin{array}{c}\text { Age (yrs) } \\
\qquad \quad \text { Range } \\
\qquad \quad \text { Mean+SD }\end{array}$ & $\begin{array}{c}16-60 \\
42.06 \pm 19.45\end{array}$ \\
\hline 2. & $\begin{array}{l}\text { Weight }(\mathrm{kg}) \\
-\quad \text { Range } \\
\text { - } \quad \text { Mean+SD }\end{array}$ & $\begin{array}{c}35-81 \\
57.82 \pm 10.64\end{array}$ \\
\hline 3. & Male: Female ratio & $68: 32$ \\
\hline 4. & $\begin{array}{ll}\text { Blood Pressure }(\mathrm{mm} \text { of } \mathrm{Hg}) & (\mathrm{Mean} \pm \mathrm{SD}) \\
\text { - } & \text { SBP } \\
\text { - } & \text { DBP }\end{array}$ & $\begin{array}{c}144.8 \pm 29.49 \\
86 \pm 16.90\end{array}$ \\
\hline 5. & $\begin{array}{l}\text { Mean CD4 count (cells/cmm) } \\
\text { - Range } \\
\text { - } \quad \text { Mean+SD }\end{array}$ & $\begin{array}{c}889-30 \\
268.70 \pm 174.55\end{array}$ \\
\hline 6. & $\begin{array}{ll}\text { Lipid Profile }(\text { Mean } \pm \text { SD }) \\
\text { - } & \text { Total cholesterol }(\mathrm{mg} / \mathrm{dl}) \\
\text { - } & \text { Triglyceride }(\mathrm{mg} / \mathrm{dl}) \\
\text { - } & \text { LDL } \\
\text { - } & \text { HDL }\end{array}$ & $\begin{array}{c}297.21 \pm 128.76 \\
415.02 \pm 280.32 \\
148.62 \pm 72.78 \\
41.95 \pm 13.74 \\
\end{array}$ \\
\hline 7. & BMI $\left(\mathrm{kg} / \mathrm{m}^{2}\right)(\mathrm{Mean} \pm \mathrm{SD})$ & $28.75 \pm 10.25$ \\
\hline
\end{tabular}

* $\mathrm{SBP}=$ Systolic blood pressure * $\mathrm{DBP}=$ Diastolic blood pressure , * BMI $=$ Body mass index

Table No. II WHO (World health organization) staging of HIV infection

\begin{tabular}{|l|c|c|c|}
\hline & WHO staging & $\begin{array}{c}\text { CD4+ T Lymphocytes count } \\
(\text { cells/ cmm })\end{array}$ & No of cases \\
\hline Stage I & HIV Infection & $>500$ & 13 \\
\hline Stage II & HIV Infection & $350-499$ & 20 \\
\hline Stage III & Advance HIV Disease (AHD) & $200-349$ & 22 \\
\hline Stage IV & $\begin{array}{c}\text { Acquired immunodeficiency } \\
\text { syndrome (AIDS) }\end{array}$ & $\begin{array}{c}<200 \\
\text { CD4+ T Lymphocyte percentage of <15 }\end{array}$ \\
\hline
\end{tabular}


Table No. III ECG findings in WHO stages of HIV patients

\begin{tabular}{|l|c|c|c|c|c|}
\hline WHO staging & Stage I & Stage II & Stage III & Stage IV & Total \\
\hline Normal & 9 & 14 & 8 & 8 & 39 \\
\hline Sinus tachycardia & 3 & 3 & 5 & 14 & 25 \\
\hline Sinus bradycardia & 1 & 0 & 0 & 1 & 2 \\
\hline Low voltage complexes & 0 & 2 & 4 & 7 & 13 \\
\hline LVH ST-T & 2 & 1 & 3 & 8 & 14 \\
\hline $\begin{array}{l}\text { Intra ventricular conduction } \\
\text { abnormalities }\end{array}$ & 0 & 1 & 3 & 4 & 8 \\
\hline $\begin{array}{l}\text { Nonspecific } \\
\text { abnormalities }\end{array}$ & 3 & 4 & 7 & 17 \\
\hline
\end{tabular}

Table No. IV Echocardiography findings in WHO stages of HIV patients

\begin{tabular}{|l|c|c|c|c|c|}
\hline WHO staging & Stage I & Stage II & Stage III & Stage IV & Total \\
\hline Normal & 6 & 9 & 13 & 15 & 43 \\
\hline $\begin{array}{l}\text { Pericarditis (+/-pericardial } \\
\text { effusion) }\end{array}$ & 0 & 3 & 3 & 5 & 11 \\
\hline Endocarditis & 1 & 0 & 1 & 4 & 6 \\
\hline Myocardial involvement & 0 & 2 & 1 & 6 & 9 \\
\hline AIDS related malignancy & 0 & 0 & 1 & 2 & 3 \\
\hline Pulmonary hypertension & 1 & 2 & 4 & 7 & 14 \\
\hline Left Vetricular hypertrophy & 2 & 6 & 4 & 10 & 22 \\
\hline $\begin{array}{l}\text { Valvular Leak } \\
\text { (MR, AR, TR) }\end{array}$ & 3 & 7 & 3 & 11 & 24 \\
\hline Diastolic dysfunction & 3 & 6 & 5 & 13 & 27 \\
\hline
\end{tabular}

\section{Discussion}

The present study is a cross sectional study, in which observations seen are compared with published literature on the same topics. Similar and contradictory findings had been elaborated and possible explanation given.

The exact prevalence of cardiac involvements in HIV/ AIDS is uncertain and it varies from 28 to $73 \%$ depending on the screening methods selected, the population studied and the definition of cardiac abnormalities. ${ }^{4,5,8}$

In the present study \% HIV infected patients demonstrate ECG abnormalities commonest being sinus tachycardia followed by nonspecific ST-T abnormalities, LVH, Low voltage complexes and intraventricular conduction defects.

Jain et $\mathrm{al}^{4}$ (2014) studied on 100 patients of HIV reported abnormal ECG findings in 18 patients. Sinus tachycardia being the commonest (15 patients) followed by nonspecific ST-T wave changes (14 patients), intraventricular conduction abnormalities (8 patients), and left atrial enlargement (4 patients).

Majid et $\mathrm{al}^{9}$ (2003) reported in their study that $75 \%$ patients of HIV had abnormal ECG findings including low voltage QRS complexes. Yupada et $\mathrm{al}^{10}$ (2004) demonstrate in their study that $52 \%$ HIV patients had right axis deviation and right ventricular hypertrophy, 39\% had nonspecific STT changes, 9\% had low QRS complexes and 4\% patients had LVH.

In the present study abnormal echocardiographic findings seen in 57\% of HIV patients (out of 100). Commonest being diastolic dysfunction followed by valvular leak, pulmonary hypertension, pericarditis and myocardial involvement. Diastolic dysfunction seen in 27 patients. It is characterized by elevated end diastolic pressure despite normal or subnormal diastolic volume. In a study carried out by Nayak $\mathrm{G}$ et $\mathrm{al}^{11}$ over 91 patients diastolic dysfunction reported in $37 \%$ patients. Since regional LV dysfunction may be the earliest stage of subsequent global LV dysfunction, the identification of this early stage is of critical importance in the management of HIV associated myocardial disease. ${ }^{12}$

Patients of HIV infections have been shown to increased risk of myocardial involvements may be due to coronary artery disease or cardiomyopathy including dilated cardiomyopathy. In this study 
myocardial involvement observed in 9 patients. It can be multifactorial including endothelial dysfunction, abnormal lipid metabolism, myocardial inflammation caused by HIV virus, cardiac autoimmunity, micronutrient deficiency, antiretroviral toxicity and tuberculous myopericarditis. ${ }^{7}$ Dilated cardiomyopathy have been associated with advanced immunosuppression and lower CD4 counts and it is independent risk factor or death. ${ }^{13}$

Jain et $\mathrm{al}^{4}$ (2014) studied on 100 patients of HIV reported LV systolic dysfunction (LVEF $<45 \%$ ) in 8 patients, out of which 3 were having dilated cardiomyopathy and 5 patients had regional wall motion abnormalities. Yupada et $\mathrm{al}^{10}$ (2004) reported LV systolic dysfunction in $37 \%$ patients of HIV. Imamuddin et $\mathrm{al}^{14}$ (2016) reported dilated cardiomyopathy in $22.72 \%$ patients and coronary artery disease in $13.63 \%$ patients of HIV.

In the present study pulmonary hypertension (PAH) seen in 14 patients. None of them had previous history or any symptoms of chronic respiratory illness. The pathogenesis of $\mathrm{PAH}$ is not clearly known but can be multifactorial. HIV may cause endothelial damage and mediator related vasoconstriction through stimulation by the envelope glycoprotein 120, including direct release and pulmonary vasoconstrictor effect of endothelin-1 (ET-1), interleukin (IL-6) and tumor necrosis factor- $\alpha$ (TNF- $\alpha)$. HIV is frequently identified in alveolar macrophages on histology. These macrophages release TNF- $\alpha$, oxide anions and proteolytic enzymes in response to infections. Effects of ART on pulmonary artery endothelial cells are unknown. ${ }^{4,15}$

In the present study valvular leak seen in 24 patients, of these mitral regurgitation being the commonest followed by TR and AR. Tricuspid regurgitation may also results in volume overload and was a specific cause of right ventricular dysfunction in a man with nonbacterial thrombotic endocarditis and end stage AIDS. ${ }^{16}$

To conclude cardiac abnormalities seen in significant number of patients with HIV.

\section{Conclusion}

The present study showed cardiac abnormalities in HIV patients in form of abnormal ECGs and abnormal 2D echocardiography. And these cardiac abnormalities are more prevalent in advanced HIV disease and AIDS.

\section{References}

1. AIDS epidemic update. World Health Organization. http://www. who.int/hiv/pub/arv/global-AIDS-update2016_en.pdf

2. UNAIDS. UNAIDS report on the global AIDS epidemic; (2018). http://www.unaids.org/sites/default/files/m edia_asset/unaids-data-2018_en.pdf

3. Lumsden RH, Bloomfield GS: the causes of HIV associated cardiomyopathy: A tale of two worlds. Biomed $R$ Int; Vol 2016/8196460

4. Kaul S, Fishbein MC, Seigel R. Cardiac manifestations of acquired immunodeficiency syndrome. AM Heart J. 1991; 122(2): 535-544

5. Jain N, Reddy DH, Verma SP, Khanna R, Vaish AK, Usman K, MD1 , Tripathi AK, Singh A, Mehrotra S, Gupta A: Cardiac Abnormalities in HIV-Positive Patients: Results from an Observational Study in India; J Inter Asso of Pro of AIDS Care 2014, Vol 13(1): 40-46

6. Lewis W. Cardiomyopathy in AIDS: a pathophysiological perspective. Prog Cardiovasc Dis. 2000; 43(2): 151-170

7. Lambert CT, Sandesara PB, Hirsh B, Sa L, Leis W, Quyumi AA, Schinazi RF, Post WS, Sperling L: HIV, highly active antiretroviral therapy and the heart: a cellular to epidemiological review; HIV Medicine june 2016; Vol 17(6): 411-24

8. Silva-Cardoso J, Moura B, Martins L, Mota-Miranda A, Rocha Goncalves F, Lecour H. Left ventricular dysfunction in HIV infected patients. Int J. Cardiol. 1998;63(1):37-45 
9. Majid S, Sailaja P: Cardiac manifestations of HIV; Frontier in Biosc May 2003(8): 305-313.

10. Yupada P, Sittiwangkul R, Suchaya S, Sirisanthana V: Cardiac manifestations in HIV infected Thai children; Ann of Trop Paed 2004(24), 153-159.

11. Nayak G, Ferguson M, David R, Terrible: AIDS Patients Care STDs. 2009; 23(4); 231-238

12. Lai H, Alban R, Tong W: HIV infection and abnormal regional ventricular function. Int J Cardiovasc Imaging. 2009; 25(8): 809-817.

13. Barbero G. Cardiovascular manifestations of HIV infection. Circulation. 2002; 106(11):1420-1425

14. Imamuddin S, Otikunta A, Pingali K, Reddy Y, Srinivas R: Cardiac Manifestation in HIV. Indian $J$ of Research. Oct 2016; 5(10):47-50

15. Pellicelli A, Barbero G, Palmieri F: Primary pulmonary hypertension in HIV disease: A systemic review. Angiology. 2001:356(17):1723-1735

16. Fink L, Reichek N, Sutton MG: Cardiac abnormalities in acquired immune deficiency syndrome. Am J Cardiol. 1984; 54(8): 1161-1163. 